\title{
A Quantitative Analysis of Integrated Reporting via CAGR on Publicly Traded U.S. Corporations Listed in the S \& P 500
}

\author{
Sean Stein Smith \\ Department of Economics and Business Lehman College, City University of New York, New York, USA \\ Email: sean.steinsmith@lehman.cuny.edu
}

How to cite this paper: Smith, S.S. (2018) A Quantitative Analysis of Integrated Reporting via CAGR on Publicly Traded U.S. Corporations Listed in the S \& P 500. Theoretical Economics Letters, 8, 1443-1459. https://doi.org/10.4236/tel.2018.88093

Received: February 7, 2018

Accepted: June 2, 2018

Published: June 5, 2018

Copyright (c) 2018 by authors and Scientific Research Publishing Inc. This work is licensed under the Creative Commons Attribution International License (CC BY 4.0).

http://creativecommons.org/licenses/by/4.0/

\section{(c) (i) Open Access}

\begin{abstract}
The business environment continues to change and evolve at a rapid pace, and the reporting process by which organizations communicate performance to external stakeholder must also change and adapt. As both financial and non-financial stakeholder become increasingly interested in not only the financial results of the organization, but how these results are achieved, management teams must take appropriate steps. Incorporating both the operational and financial results of the organization into data communicated to internal and external users remains a fiduciary responsibility of management professionals across industry lines. Integrated reporting, although not a panacea for short-termism and other pressures on organizations, does provide a vehicle for more comprehensive financial reporting. This research examines both the literature and academic support for integrated reporting, and, as of the date of this research, implications that adopting such a framework has a financial performance.
\end{abstract}

\section{Keywords}

Integrated Reporting, Multiple Capital Model, Accounting, Finance, Technology

\section{Introduction}

As the global business environment continues to become increasingly integrated and digitized in nature, the following reality is apparent for management professionals across industry lines. Stakeholder groups, which can be summarized as any and all non-financial institutions or organizations interested in the performance of the business, play an ever larger role in how management teams inte- 
ract with the marketplace. Financial performance, clearly, continues to dominate not only how market analysts and other participants evaluate organizations, but also play a prominent role in how management professionals are judged. In addition to this traditional lens through which organizations are analyzed, however, the influence of stakeholders also appears to be making a collective change to how organizations report the results of operations. Particularly in the aftermath of the financial crisis, and the rise of socially conscious investing methodologies, investors and stakeholders appear increasingly interested in not only the financial performance of the firm, but how these results are generated.

Despite the prevalence of such trends, in both practitioner and scholarly literature, there remains a stumbling block towards full integration of financial and non-financial reporting into the reporting structure of an organization. While it is readily apparent and clear that a broad variety of issues play a role in how successful an organization is from a financial perspective, quantifying and standardizing these different data streams remains an ongoing challenge for many organizations. Management decision making relies on a consistent supply of information that is comparable, consistent, and reported continuously over periods of time. Some organizations, some of which will be analyzed and examined throughout this research, have adopted standalone sustainability reporting structures, but this alone is insufficient for comparative and widespread adoption. The literature review component of this research brings together several disparate areas of research to report and analyze the progress and iterations of reporting gaining acceptance throughout the marketplace. Secondly, and constituting the quantitative portion of this research, is a comparison designed to measure whether or not a more stakeholder oriented method of reporting generates superior financial performance.

\section{Literature Review}

Prior to constructing a quantitative methodology to analyze the financial performance of North American organizations that have adopted integrated reporting versus comparative firms that have not, it is logical to conduct a review of the existing scholarly literature. Analyzing both seminal and current academic research conducted and focused on this area is critically important to understanding the implications of any findings generated as a result of this study. Taking into account the state of academic analysis and research adds additional validation to the market driven conversation currently taking place in these various areas. Institutional investors, including but not limited to pension funds, endowments, and other institutional sources of capital to the market are focusing on these broader societal issues, but this alone is insufficient to understand the quantitative implications of said changes. Layering into this conversation and debate quantitative research also provides fertile grounds for additional conversation, analysis, and research into the ramifications of adopting a stakeholder-centric approach to management reporting. 


\subsection{Stakeholder Theory}

Stakeholder theory forms the foundation and cornerstone for a broader base of management reporting and analysis, which appears to be in alignment with current trends emerging in the marketplace. In essence, a stakeholder based approach to management focuses on incorporating the needs and expectations of non-financial stakeholders into operational decision making and the management reporting process. Regardless of which specific industry and organization the management team operates within, project based management and effectively evaluating projects is a core responsibility of management. Effectively and efficiently developing projects represents an opportunity for management to incorporate stakeholder expectations and requirements, especially those that integrate and embed goals and objectives linked to different stakeholder groups [1]. Integrating stakeholder expectations not only may result in a more successful project, but can also enrich the project management process itself, transforming it into a higher level competency. Additionally, and interestingly in the context of the current marketplace, stakeholder expectations and theory is often correlated with the notion of sustainability, and reporting different types of sustainability related information.

Interest in sustainability, operating in an environmentally friendly and conscious manner, and communicating this information to the broader stakeholder community appears to be emerging as a critical issue for the investor community. With trillions of assets ear marked for sustainability related investments, the directionality of this change is readily apparent. Additionally, and covered in mainstream business communication, there is pressure being brought to bear on endowments, pension funds, and other large institutional sources of capital to divest from investments linked to environmentally detrimental activities. This pressure for stakeholder based reporting and management has implications for organizations on both a national and international basis [2]. Specifically, sustainability, both from a managerial and financial perspective, has a suite of implications for management professionals and organizations. It is clear that stakeholder theory, and the specific requirements and expectations of non-financial stakeholders, can and is having an influence of how management professionals evaluate decisions.

In addition to the implications of sustainability, the broader adoption and integration of stakeholder theory into the reporting and communication process appears to be directly linked to the increased appetite for non-financial information. Non-financial information, including but not limited to environmental, operational, and regulatory issues, can have significant implications for how the organization performs in the medium to long term. That said, it is important to balance, and analyze, the differences that may arise from organizations integrating corporate responsibility initiatives on a superficial or more integrated basis [3]. Different strategies and tactics, as they are related to different industries, will have an effect on the specific implementation steps, but across the board, 
non-financial information is of increasing importance. The growing amount of non-financial information, including reporting, that is collected and disseminated by organizations to the marketplace is worth mentioning for the following reason. Included in this dialogue and ongoing conversation related to sustainability and stakeholder reporting is the importance of ethics and ethical decision making to stakeholder oriented decision making [4]. Stakeholder, including both financial and non-financial stakeholders, appear to be increasingly interested in not only profits of the organization, but how specifically these results are obtained.

As organizations integrate and fulfill the needs of non-financial stakeholders, the accounting information systems of these organizations must be able to keep pace. Digitization and other technological changes have disrupted large swaths of the business landscape, and the accounting profession is not immune from these pressures. Interestingly, the increased integration of technology into the accounting and financial reporting process also opens the door to more comprehensive reporting.

\subsection{Integrated Reporting}

The concept of integrated reporting, at the core of issue, is not a particularly innovative or new issue or idea. Building on the foundation laid over several decades, including different types of sustainability and non-financial reporting templates, integrated reporting appears to represent a culmination of previous ideas rather than entirely new concepts. Put simply, integrated reporting allows organizations and management teams to present a more comprehensive view and representation of how the organization is actually performing. Supported and developed by the International Integrated Reporting Council, this reporting framework seeks to address some existing gaps in stakeholder theory and associated reporting options. At a fundamental level, the reporting process must result in quality information that is consistent, comparable, and delivered on a recurring basis-accounting professionals and firms must fulfill these requirements. This helps address some of the issues, including a lack of standardization and consistency with reporting non-financial, including sustainability information [5]. In order to produce the quality and volume of information that is expected by market participants, including financial and non-financial data, management accounting professionals must be integrated within the decision making process. Drilling in specifically into this concept reveals several points of emphasis that should be incorporated into an analysis of integrated reporting, including attempting to understand the financial impacts of adopting such a framework.

Bringing together various streams of organizational data and information are connected to other areas incorporated into this research and analysis. First, the growing influence of stakeholders focused both on financial and the non-financial performance of the organization, provides a logical framework for 
increasingly holistic analysis [6]. Included in the category of stakeholder groups includes institutional investors, who would fall into the category of traditional financial shareholders, and other, non-traditional stakeholder groups. Second, other stakeholder groups that include environmental groups, consumer advocacy groups, and regulatory organizations are clearly proponents of a more comprehensive view of organizational performance. In order to make this transition effectively, however, management professionals must develop and utilize a comparable framework and methodology to communicate said information effectively.

First, at the core of the integrated reporting framework is the idea of a multiple capital model, which quantifies the following reality. Financial results and information are reported on a virtually continuous basis, and attract the majority of the attention from market participants, but represent the end result of operations versus the core functionality of the organization. In order to produce the results and performance that form the foundation of management decision making, a variety of other sources must align and perform on a high level. Second, accounting professionals, specifically those employed within organizations instead of those employed in an external or consultative role, appear to be well positioned to assist in the adoption of integrated reporting. Generating quantitative information, and reporting and communicating the ramifications of these different sources of information represent core competencies of the profession [7]. Third, and perhaps most interestingly for this research, is the reality that the traditional definition and representation of capital appears to be insufficient within the current marketplace. Capital, specifically a current representation of capital as strictly the financial resources and capabilities available to an organization, is an important facet of capital but does not represent the totality of what capital means for organizations.

\subsection{Multiple Capital Model}

Leveraging the increased importance of stakeholder concerns and importance of reporting a more comprehensive view of the organization, including both short term financial results and longer term strategic organizations, the idea of a multiple capital model appears to be a logical extension. Drilling down into the idea itself, there are six types of capital that are incorporated into the idea of integrated reporting. Types of capital include financial, manufactured, intellectual, natural, social and relational, and human, and while different capital classes will be more important for some organizations versus others, some types of capital are applicable to virtually every institution. Building on the earlier research and statements illustrating the increasing integration of technology and accounting, one of the most important changes in the profession is the influence of technology. That said, however, increasing utilization of technology in and of itself is insufficient to deliver the type and variety of information that is now expected or organizations large and small. 
Analyzing and reporting the inputs and outputs related to these different capital classes is reliant both on technology advancements in the accounting field, and the importance satisfying stakeholder demands. At its essence, the multiple capital model represents a quantitative representation of traditionally qualitative data, but this data is especially important for higher level decision making. Different classes, and types of capital have been readily apparent to management decision makers for a significant period of time, but rarely have these different sources of funding, and potentially competitive advantage, been quantified and reported on a consistent basis. Ensuring that stakeholders, including consumer and regulatory focused stakeholders, receive the appropriate quantity and quality of information can, and is, playing a large role in the communication of information the marketplace. Taking advantage of technology, including blockchain and artificial intelligence, allows management professionals to generate and report increased amounts of information the senior level decision makers. Gathering, organizing, and reporting different classes of information and operational data presents the following situation-how can management accountants and management leverage technological advances to further the business of the enterprise?

The multiple capital model, outlined in greater depth below, the overarching importance of a multiple capital model must be acknowledged and examined. The six types of capital, which includes financial capital, may initially seem like an excessive amount of data to collect and report on an ongoing basis, but this provides an incomplete view of the situation. While financial information and financial capital may attract the largest amount of analysis and information by market analysts and shareholder groups, this information is merely the end result of operational results and activities. Operational data, summarizing the activities of organizational activities, and linking operations to financial results do not represent new trends or insights, but the ability to standardize said information is a substantial step forward. The multiple capital model, quantifying and reporting the different sources of information generated within an organization, builds the bridge between internal information and external reporting.

Summarizing the implications of a multiple capital model requires that both management and accounting professionals understand and analyze the implications of a stakeholder-oriented environment. Technological advances and changes to the broader business landscape have resulted in increased awareness of how organizations are performing on a continuous basis, and such an advance includes both financial and non-financial measures. Drilling in specifically to the implications and ramifications facing the accounting profession, there appear to be two broad based changes that continue to influence how the accounting profession interacts with the broader business landscape.

First, in order to gather, analyze, and report on a broad array of information, and do so in a timely and consistent manner, accounting practitioners must become increasingly integrated with technologically oriented functional groups. As 
larger numbers of practitioners are tasked with assisting, or even leading, technology related projects, this shift appears to already be well underway. Second, and perhaps most interestingly, is that the role that accounting plays in the management decision making process. Put simply, in order to make effective decisions with these every larger amounts of information, the experts at understanding this information, namely accounting professionals, should increasingly be included in the decision making and approval process. Analyzing these trends and influential changes currently underway in the marketplace also provides management professionals an opportunity to effectively leverage said changes to improve the value additive actions underway in the profession.

\subsection{Technological Advancements}

Clearly, the proliferation of technology within business activities at large, and specifically the corporate accounting and finance functions, has generated large amounts of change and disruption within the profession. In order to adopt an integrated reporting framework, however, requires that professionals embed changes and advances to the technological framework in the marketplace into accounting processes. Even more so, as technology becomes increasingly integrated into operational issues, the implications for how management teams make decisions become readily apparent [8]. Technology, and changes in technology tools put into place at various organizations, are alone insufficient to generate the necessary changes required of both management professional and accountants. Taking a broader step back, it is evident that the process by which decisions are made and evaluated must also evolve and keep pace with technological advancements. Specifically, and drilling into the capability of an organization to report a more comprehensive view of how the organization is performing, two distinct trends appear to be dominating the debate.

Blockchain technology, in addition to creating and proliferating the spread of alternative currency instruments, provides the groundwork and foundation for a more continuous reporting structure to be put into place at organizations large and small. In essence, how blockchain technology works is that every transaction, and therefore the information contained within that transaction, is encrypted between the parties involved in that specific transaction [9]. Utilizing a unique identifier, which is specific to each participating entity or institution, allows the transactions to be processed anonymously while ensuring the security of the transaction. Each party included in the transaction is provided with both a unique identifier, as well as with the means by which the specified parties can unencrypt the specific information. Applicable to this research is the connection between blockchain technology, integrated reporting, and the variety of information available to management professionals.

Additionally, and possibly more important for the accounting field and accounting professionals at large, are the implications of artificial intelligence for both gathering information and leveraging the increased availability of informa- 
tion to management professionals [10]. Taking into account both the different forms of capital available and at the disposal of management professionals, artificial intelligence and the integration of information systems into accounting processes is particularly relevant. Whether the tools and processes are applied to processing invoices, transactions, and examining certain documents, or recording and verifying the payments and verification of customer invoices, AI is already disrupting the accounting profession [11]. Advances in both accounting technology on a standalone basis, and the integration of these tools into the broader decision making process, influence both the reporting aspect of information and the underlying data driving the reporting process [12]. Harnessing this information, capabilities, and tools that are of emerging importance in the marketplace, and applying it to the concept of multiple capitals, provides a quantitative opportunity for accounting professionals to elevate the profession to a higher level strategic role.

\subsection{The Long Term View}

In the marketplace, there appears to be a debate underway between the ability of management to perform on a short-term basis and the capability of organizations to enhance shareholder, and stakeholder value, over the longer term. Stakeholder theory clearly emphasizes the importance of reporting, documenting, and communicating information to both financial and non-financial stakeholders. Operating in a sustainable manner, in alignment with creating long term value for all interested parties, requires integrating the needs of stakeholders within the content of non-financial reporting [13]. Creating value in the marketplace, especially in an increasingly global and digitized economy, requires that management professionals incorporate expectations and requirements of stakeholders into the reporting process. Developing value, from a longer term perspective, is currently the focus of management professionals and market analysts, but a fundamental issues remains potentially unaddressed. In spite of increased interest from market participants and analysts, the primary focus of many management professionals remains on the shorter term metrics and information reported on a quarterly basis. Bridging this gap, from the shorter term to the longer term, is where the potential opportunity and benefits of integrated reporting can be recognized.

Incorporating stakeholder expectations and requirements, into both the reporting and communication processes of an organization, allows management to more accurately and fully represent the actions underway at the institution. Stakeholders, whether they are financial or non-financial in nature, expect certain levels of information and consistency in terms of the information provided [14]. Additionally, and more specifically applicable to this research study, is whether or not adopting a comprehensive view of organizational performance will result in financial benefits. Media coverage and analysis of the benefits of taking the longer term view continue to dominate business conferences and 
publications, but a quantitative study focusing on this area appears to be lacking. Drilling in specifically, the connection between integrated reporting, long term value creation, and organizational success appears to become clearer. Building into the reporting framework a methodology of documenting external and internal sources of organizational value allows both management professionals and accountants to document the progress and performance of the organization over time.

\subsection{Developing Reporting and Assurance Standards}

A fundamental challenge that continues present itself to practitioners and academic researchers attempting to expand the utilization of sustainability and non-financial reporting is a lack of standards and metrics for practitioners to utilize. Quantitative data is what, in essence, drives the majority of management decision making and allows organizations to be evaluated versus both peer groups and past performance. Core tenets and benefits of accounting and finance information include the following characteristics; comparability, consistency, relevancy, and timeliness. Developing standards, reporting templates and metrics, and other key performance indicators will allow accounting practitioners, management decision makers, and external analysts to consistently analyze these different types of information. Additionally, by integrating the needs and preferences of professional investors for non-financial information, organizations can report different types of information, and better understand the needs of the marketplace [15]. It is true that numerous attempts and methods for developing such standards have dominated the market at various times, but a lack of institutional support and broad based practitioner buy-in has limited the effectiveness of these measures. Analyzing the global business landscape in the aftermath of the financial crisis and global recession, there appears to be increasing support for current measures across industry and geographic boundaries.

Examples of these advances in developing standards include the work of the International Integrated Reporting Council (IIRC), the Sustainability Accounting Standards Board (SASB), and the numerous white papers and publications put forth by various professional accounting organizations. Coordination between these various organizations and NGOs, in addition to the investor support evident in the creation of various, represent increased stakeholder support for a more comprehensive view of organizational performance. Linking back to the concept introduced previously, that of a multiple capital model and a redefinition of what capital means to an organization, the connection appears to be clear. With the increasing support and buy-in from institutional, professional, and academic sources, developing metrics and comparable sources of information is becoming a focus of interested stakeholders.

The importance of developing assurance and attestation standards is something that may initially be overlooked by various stakeholder groups, but is especially important to increased adoption and implementation of integrated fi- 
nancial reporting [16]. Accounting information and data, in order to be used effectively and efficiently by internal and external stakeholder groups, must fulfill possess several characteristics. Data and information must be consistent, timely, relevant, and replicable over multiple periods of time, all of which accounting professionals have experience in preparing. As the comparability of different types of information, both operational and financial information, increases the reliability of this information will also increase.

One aspect of this debate is whether or not the of metrics is most effective on an industry by industry basis, or by the creation of broader based reporting standards for large swaths of the economy. Sourcing and developing finance that can be reported in a sustainable manner is something of interest and importance for virtually every organization, and can be a differentiating factor in a globalized landscape [17]. Evidence and some research does seem to support the construction of industry specific metrics and tools, which does appear logical when viewed through the reality that different industries require different levels and amounts of information. That said, however, it is also worth noting that, despite industry differences, many organizations are evaluated using similar metrics and information. It does not appear that such a practice will change, regardless of whether the information reported is done so as part of an integrated report, or a traditional financial filing, such as $10-\mathrm{K}$ or $10-\mathrm{Q}$.

\subsection{Value Proposition of Integrated Reporting}

At the core of any reporting methodology, management initiatives, or strategic project undertaken by an organization is the value generated by the project or initiative to the organization and stakeholder groups. Especially in the context of the integrated reporting framework, the true benefit and value add in the process is the value that this process creates in the medium and long term. Specifically, in a globalized business environment where not only business actions are taken into account, but trade relationships and balance must also be factored into the analysis of the impact of reporting on financial performance [18]. Bringing together a variety of data streams, both financial and non-financial information, creates a more comprehensive and holistic view of organizational performance. Particularly in a business environment where management professionals are judged not only by the short term performance of the firm, but the sustainability of said performance, a long term perspective is an imperative. While sustainability is often thought of as an environmentally oriented action, in the context of this research it has a dual meaning. Sustainable performance and operations, taken within the purview of a stakeholder business landscape, means that the performance must be replicable over certain periods of time. To generate such consistent earnings, it is important note, also requires that management incorporate, analyze, and report a variety of data and information over periods of time for comparability purposes. Such a connection is important for the analysis of integrated reporting within the context of this analysis, forming the founda- 
tion of the 4-year testing period analyzed below.

\section{Method}

This study attempts to quantitively analyze the possible relationship between organizations that have implemented integrated financial reporting, and the financial performance of those firms over a defined period of time. For the purposes of this research the time period in question will be 2013-2016, a 4-year period of time that is both subsequent to the financial crisis and measures a period of time that integrated reporting has been adopted by various organizations. This 4-year data period was utilized for the following reasons. First, it excluded some of the sharply increased volatility the market experienced during the decline in market values during the financial crisis, and subsequent recovery. Second, a 4-year period provides sufficient data to begin a preliminary analysis of the emerging topic of integrated financial reporting. Third, and arguably most important for this research, integrated reporting amongst North American companies only began to achieve wider spread adoption beginning in 2013, after implementation and adoption had spread in other markets. The calculation of CAGR results was conducted using publicly available information documenting the earnings of the selected organizations. Upon collection of this earnings data, a publicly available CAGR calculator was used to finalize the rates of return documented below.

Drilling in specifically to the parameters of this research study there will be 10 organizations analyzed as a part of this study. The specific firms analyzed in this research study are American Electric Power, Canadian REIT, Clorox, Coca-Cola, Entergy, General Electric, JLL, PotashCorp, Smithfield, and Vancity. Spread different geographic and industry lines, such a cross section of organizations represents an adequate breadth of organizations to examine and compare versus peer groups. Integrated financial reporting represents a more comprehensive and holistic view of how and organization is actually performing over the medium to long term, and including various organizations from different industry sectors reinforces the validation of a stakeholder based of management in the business environment. These organizations are utilized for this research study both because they have implemented integrated financial reporting during the time period of this research study, and have been highlighted as notable examples by the International Integrated Reporting Council via the examples database located on the organizations homepage.

Comparing the performance of these organizations versus a broad based index such as the S \& P 500 is a logical place to begin this analysis for several reasons. First, since the breadth of organizations studied include numerous industries and fields, comparing these organizations versus a broad based index is logical. Second, since the concept of integrated financial reporting, by default, embraces a more comprehensive view of financial performance in a stakeholder environment, a comparative study versus a global index increases relevancy. Lastly, since 
integrated reporting represents a global evolution of many stakeholder and non-financial reporting frameworks, a global index provides an adequate baseline for testing and examination.

In addition to the qualitative analysis and that has taken place throughout the research, a quantitative study of this idea also appears to be appropriate. Management decisions, regardless of the specific industry in question or size of the organization, are in large part based on the quantitative data and information reported to external users. Analyzing the performance of organizations that have adopted an integrated reporting framework, especially in the context of market peer groups, allows users of this research to generate meaningful results. Comparing the financial performance of these organizations in a quantitative manner requires that a baseline tool or metric, which for this study is compound annual growth rate (CAGR). Focusing specifically on the CAGR of a firms profits creates a comparable, consistent, and benchmark that can be cited, expanded upon, and discussed by both internal and external users of these financial statements. Importantly, this study leverages only publicly available information, which increases the replicability, comparability, and ability of users to build on this research.

\section{Hypothesis}

$\mathrm{H1}$ : The underlying hypothesis of this study is that organizations utilizing an integrated financial report will outperform the S \& P 500, a global stock market index, using CAGR as an applicable metric.

$\mathrm{H0}$ : The underlying hypothesis of this study is that organizations utilizing an integrated financial report will not outperform the S \& P 500, a global stock market index, using CAGR as an applicable metric.

\section{Findings}

Upon reviewing the information related to the organizations outlined and listed above, and leveraging publicly available information, this study was able to be completed using the metric of operating income. Operating income appears to be a logical metric to use for this study as it eliminates the differences in scale and scope that could otherwise influence the results of this information. Second, operating income forms the basis for how management professionals are often judged, and plays a large role in computing the financial metric of earnings per share (EPS), which every publicly traded organization must report to the market on a continuous basis. Taking these factors into account, and gathering the information related to operating income, the following data emerged.

Comparing the organizations in this study versus the performance of the $S \&$ P 500 during the same time period, which generated a CAGR of 5\%, obtained using a publicly available chart of closing and opening prices, the results were varied. It is worth noting at this time that Smithfield was acquired in 2013, and Vancity is a privately owned and operated organization. Due to these con- 
straints, conducting the proposed analysis of these organizations was not possible. Additionally, since the performance of Entergy, closely linked to the oil and natural gas markets, plummeted during the proposed period, the proposed CAGR analysis was not applicable. Using a publicly available CAGR calculator, and using operating income information cross referenced between Google Finance and the SEC, the rates of return for these organizations were computed. Documented below, and illustrated by Figure 1, the variance in returns achieved is readily apparent.

- American Electric Power generated a CAGR of (19.13\%)

- Canadian REIT generated a CAGR of 3.93\%

- Clorox generated a CAGR of $3.8 \%$

- Coca-Cola generated a CAGR of 5.31\%

- General Electric generated a CAGR of 0.78

- JLL generated a CAGR of $4.55 \%$

- PotashCorp generated a CAGR of (35.94)

Drilling into the data and findings generated by this research study, it does not appear that any of the specific organizations analyzed as a part of this research outperformed the S \& P 500 average as a whole during this period. While it is clear that two of the organizations as a part of this study, American Electric Power, and PotashCorp, generated negative returns during the period in question, these results are worth additional analysis. AEP operates in a highly regulated environment that requires continuous capital investment, as well as contending with regulations, evolving environmental conditions. Additionally, in such a highly regulated business landscape, rates of return can be influenced by regulatory authorities, as well as decisions made by management in terms of investing for the long term. Following up on these issues and conditions, PotashCorp operates in the highly competitive and variable business landscape with input costs outside of the control of management. Commodity prices, and the volatility of these prices have had a tremendous influence of how organizations

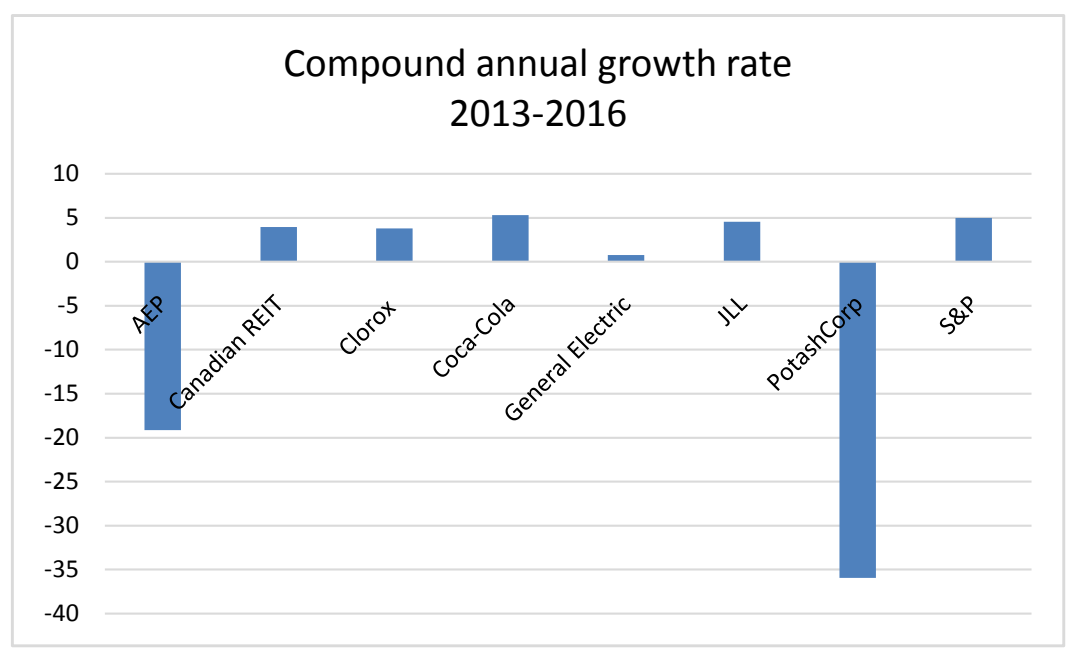

Figure 1. Chart of CAGR of selected organizations from 2013-2016. 
operating in these fields perform and generate returns in the marketplace. Figure 2 also demonstrates the volatility of these results, including the fact that some organizations utilizing an integrated reporting during period did, in fact, generate a negative CAGR for the time period in question.

Taking a step back and analyzing these results in the broader context of market performance, there does not appear to be a causal connection between these organizations and financial performance that is superior to a market index. That said, it is important to note that while this specific study does not appear to generate results that illustrate a relationship between integrated reporting and outperforming the broader marketplace, there are findings and future directions appealing to both practitioners and academics. With the underlying trends and forces orienting the marketplace toward sustainability, operational data, and the importance of a more comprehensive view of organizational performance, the trend is clear. Integrated reporting does not appear, in any marketplace, to represent a fad or short term initiative that will fade away over the medium to long term. Rather, the reporting framework and information contained therein is of increasing interest to stakeholder groups, institutional investors, and financial shareholders. Interestingly, and expanded upon below, interest and utilization of integrated reporting, and a stakeholder oriented mindset, continue to increase both in the United States and in other global markets.

\section{Conclusions}

This research article set out with a dual purpose, to both analyze existing literature and studies linked to integrated financial reporting and stakeholder theory, and to examine whether current implementation generated superior results versus a broad based index. While the results of this analysis did not seem to establish a causal linkage between integrated reporting and financial results, the underlying trend toward a more comprehensive view of reporting is apparent. Depending on the specific geographic region in question, adoption of sustainability, corporate governance, and other more holistic reporting may proceed at differing speeds, but stakeholders are increasingly interested in such information. As

\begin{tabular}{|l|r|}
\hline \multicolumn{1}{|c|}{ Organization } & \multicolumn{1}{c|}{ CAGR } \\
\hline AEP & $-19.13 \%$ \\
\hline Canadian REIT & $3.93 \%$ \\
\hline Clorox & $3.80 \%$ \\
\hline Coca-Cola & $5.31 \%$ \\
\hline General Electric & $0.78 \%$ \\
\hline JLL & $4.55 \%$ \\
\hline PotashCorp & $-35.94 \%$ \\
\hline S\&P & $5.00 \%$ \\
\hline
\end{tabular}

Figure 2. Positive versus negative returns, as per CAGR, 2013-2016. 
integrated reporting continues to attract the focus, attention, and intellectual investment of accounting and other professional organization, it is logical to conclude that further research in this area is required.

The limitations of this study are logical and straight forward to understand, and also applicable to other quantitative studies in the area of financial reporting. First, the time period in question is limited in duration, limited to 2013-2016, which does impost limits on the applicability of this research study. That said, and importantly, the fact that this research uses publicly available data means that, over time, this study and analysis can, and should, be extended and built upon moving forward. Second, integrated reporting is an emerging area of analysis and financial reporting, so there is a limited field of research and availability to use for benchmarking purposes. This, while serving as a limitation of this research, also lends itself to the replication and expansion of this study by future research and practitioners.

Accounting and financial information are what drive the short term assessments and decision making processes, usually underpinned by periodic earnings estimates and reports, but that represents an incomplete view of true organizational performance. Operational data, corporate governance initiatives, and the importance of integrating sustainability throughout business operations represent factors that drive business performance and financial information. Reporting, quantifying, and standardizing the different types of information are what, examined from a higher level perspective, form the foundation and basis for strategic planning and analysis. Integrated reporting, while not a panacea for the shortcomings and shortfalls of current reporting structures and communication processes, appears to represent a path forward for organizations. With growing implementation and adoption on a global basis, and across different industry lines, the value add of integrated reporting appears to only be growing and expanding on a continuous basis.

\section{Future Directions}

As an embedded component of this research study, the findings, results, and structure were intended to be applicable and relevant for both practitioners and academics. Academic researchers can build on this analysis and research, comparing the performance of organization using stakeholder reporting frameworks versus broader market metrics. Specifically, as integrated reporting becomes more widely accepted and utilized, the available data for comparative purposes will only increase. Practitioners seeking to leverage and expand on this research and findings, specifically the intersection of technology and accounting professionals, will find a plethora of information contained both in this research and its findings.

Specific research aims that can, and should, build upon this research study include but are not limited to the following areas: First, a continuation and expansion of this study should be conducted as integrated reporting becomes more 
common, and is implemented at an increasing number and types of organizations. This will both provide an opportunity to evaluate the effectiveness of integrated reporting, and an analysis of industry specific trends. Second, a connection and linkage between emerging technological trends such as blockchain, crypto currencies, and artificial intelligence can be layered upon the adoption trends of integrated reporting. Compiling and reporting a wide variety of information, necessary to issue an integrated report, will inevitably require greater integration of technology throughout the accounting profession. Last but not least, the potential for research and thought leadership in the areas of accounting and financial services can be built upon this research. With shareholders and stakeholders alike expecting and, in some cases, requiring more comprehensive information, accounting and finance professionals must develop appropriate competencies to address these needs.

The accounting profession is changing, evolving, and must keep abreast of changes; integrated reporting is just one of these changes. Taking that into account, examining the intersection of technological changes and accounting changes, and making quantitative decisions based on these changes will help keep the profession relevant, well-informed, and valuable in the $21^{\text {st }}$ century.

\section{References}

[1] Eskerod, P., Huemann, M. and Ringhofer, C. (2015) Stakeholder Inclusiveness: Enriching Project Management with General Stakeholder Theory. Project Management Journal, 46, 42-53. https://doi.org/10.1002/pmj.21546

[2] Gao, J. and Slawinski, N. (2015) The Impact of Stakeholder Management on Corporate International Diversification. Business \& Society Review, 120, 409-433. https://doi.org/10.1111/basr.12061

[3] Shabana, K.M. and Ravlin, E.C. (2016) Corporate Social Responsibility Reporting as Substantive and Symbolic Behavior: A Multilevel Theoretical Analysis. Business \& Society Review, 121, 297-327. https://doi.org/10.1111/basr.12089

[4] Reiter, S.L. (2016) Corporate Profit, Social Welfare, and the Logic of Capitalism. Business \& Society Review, 121, 331-363. https://doi.org/10.1111/basr.12090

[5] Bouten, L. and Hoozée, S. (2015) Challenges in Sustainability and Integrated Reporting. Issues in Accounting Education, 30, 373-381.

https://doi.org/10.2308/iace-51093

[6] Vaz, N., Fernandez-Feijoo, B. and Ruiz, S. (2016) Integrated Reporting: An International Overview. Business Ethics: A European Review, 25, 577-591. https://doi.org/10.1111/beer.12125

[7] Brown, V.L. and Kohlbeck, M.J. (2017) Providing Assurance for Sustainability Reports: An Instructional Case. Issues in Accounting Education, 32, 95-102. https://doi.org/10.2308/iace-51582

[8] Viscelli, T.R., Hermanson, D.R. and Beasley, M.S. (2017) The Integration of ERM and Strategy: Implications for Corporate Governance. Accounting Horizons, 31, 69-82. https://doi.org/10.2308/acch-51692

[9] Drew, J. (2017) Real Talk about Artificial Intelligence and Blockchain. Journal of Accountancy, 224, 1-6. 
[10] Murthy, U.S. (2016) Researching at the Intersection of Accounting and Information Technology: A Call for Action. Journal of Information Systems, 30, 159-167. https://doi.org/10.2308/isys-51413

[11] Banham, R. (2017) Digital Disruption Creates Opportunities. Journal of Accountancy, 224, 1-2.

[12] Vollmer, S. (2017) Assessing the Global State of the Profession. Journal of Accountancy, 224, 1-4.

[13] Bradford, M., Earp, J.B., Showalter, D.S. and Williams, P.F. (2017) Corporate Sustainability Reporting and Stakeholder Concerns: Is There a Disconnect? Accounting Horizons, 31, 83-102. https://doi.org/10.2308/acch-51639

[14] de los Reyes Jr.G., Scholz, M. and Smith, N.C. (2017) Beyond the "Win-Win": Creating Shared Value Requires Ethical Frameworks. California Management Review, 59, 142-167. https://doi.org/10.1177/0008125617695286

[15] Cohen, J.R., Holder-Webb, L. and Zamora, V.L. (2015) Nonfinancial Information Preferences of Professional Investors. Behavioral Research in Accounting, 27, 127-153. https://doi.org/10.2308/bria-51185

[16] Du, S., Yu, K., Bhattacharya, C.B. and Sen, S. (2017) The Business Case for Sustainability Reporting: Evidence from Stock Market Reactions. Journal of Public Policy \& Marketing, 36, 313-330. https://doi.org/10.1509/jppm.16.112

[17] McGuigan, N., Sin, S. and Kern, T. (2017) Sourcing Sustainable Finance in a Globally Competitive Market: An Instructional Case. Issues in Accounting Education, 32, 43-58. https://doi.org/10.2308/iace-51304

[18] Reich, U. (2016) Value “Added”: Why Consistency in Aggregation Is Essential for Global Accounting Standards, and How to Achieve It. Journal of Economic \& Social Measurement, 41, 307-327. https://doi.org/10.3233/JEM-160431 